\title{
PRODUÇÃO E DECOMPOSIÇÃO DE SERAPILHEIRA EM POVOAMENTOS DE TECA NO ESTADO DE MATO GROSSO, BRASIL
}

\author{
LITTER PRODUCTION AND DECOMPOSITION IN TEAK POPULATIONS IN MATO GROSSO \\ STATE, BRAZIL
}

Tania de Fátima de Deus Rosa ${ }^{1}$ Walcylene Lacerda Matos Pereira Scaramuzza ${ }^{2}$ Isadora Pires Feitosa ${ }^{3}$

Fernanda Feboli Mansano de $\mathrm{Abreu}^{3}$

\section{RESUMO}

O presente estudo teve como objetivos estimar a produção, a taxa de decomposição, o tempo médio de renovação e decomposição da serapilheira em povoamentos da espécie Tectona grandis Linn. F. (Teca). O estudo foi realizado em três povoamentos de teca localizados no município de Nossa Senhora do Livramento - MT. Para as coletas da serapilheira foi delimitada uma área de 1 (um) ha em cada talhão com idades de cinco, seis e sete anos, na qual foram distribuídos, aleatoriamente, 20 coletores de madeira suspensos e vazados, com área de $0,64 \mathrm{~m}^{2}$. O material vegetal depositado nos coletores foi recolhido a cada 30 dias, durante 12 meses, levado ao laboratório separando-se folhas, ramos (menores que um centímetro de diâmetro) e miscelânea, e depois de secos foram pesados. A serapilheira produzida nos talhões com sete, seis e cinco anos de idade foi, respectivamente, 7.280,25; 6.739,42 e 6.419,61 $\mathrm{kg} \mathrm{ha}^{-1}$. As folhas representaram $86 \%$ do total de serapilheira depositada, os ramos, $4 \%$, e as miscelâneas, $10 \%$. As constantes de decomposição da serapilheira (K) nas árvores com cinco, seis e sete anos de idade foram, respectivamente, de 0,54; 0,60 e 0,58. O tempo médio de renovação, em anos, foi de 1,84 (671 dias) aos cinco anos, 1,67 (609 dias) aos seis anos e 1,71 (624 dias) aos sete anos. Para que ocorresse a decomposição de $50 \%$ da serapilheira, o tempo médio estimado foi de 1,28 anos (467 dias), 1,15 anos (419 dias) e 1,19 anos (434 dias) para as árvores com cinco, seis e sete anos, respectivamente. Para a decomposição de $95 \%$ da serapilheira, o tempo médio estimado foi de 5,53 anos (2.018 dias), 5,00 anos (1.825 dias) e 5,14 anos (1.876 dias) para a mesma sequência das idades.

Palavras-chave: serapilheira; Tectona grandis; taxa de decomposição.

\section{ABSTRACT}

The objective of this study was to estimate the litter production and decomposition rate, litter renewal and decomposition period in Tectona grandis Linn. F. (Teca) populations. The research was carried out in three different populations located in the city of Nossa Senhora do Livramento-MT state. Litter fall was collected from a limited forest area of 1 (one) ha containing plots with five, six and seven years old, from 20 wood collectors suspended and cast, covering an area of $0,64 \mathrm{~m}^{2}$. The accumulated material was collected every 30 days, for 12 months, sent to the laboratory and segregated into leaves, branches (less than one centimeter in diameter) and mixed material, then dried and weighed. The litter fall collected from plots with seven, six and five years old had, respectively, 7,280.25; 6,739.42 and $6,419.61 \mathrm{~kg} \mathrm{ha}^{-1}$. The leaves corresponded to $86 \%$ of the deposited litter, branches, $4 \%$, and mixed material, $10 \%$. The decomposition rate constant (K)

1 Engenheira Florestal, MSc., Universidade Federal de Mato Grosso, Laboratório de Nutrição Mineral de Plantas, Av. Fernando Correa da Costa, 2367, Bairro Boa Esperança, CEP 78060-900, Cuiabá (MT), Brasil. taniafdr@yahoo.com.br

2 Engenheira Agrônoma, Dr ${ }^{\mathrm{a}}$., Professora da Universidade Federal de Mato Grosso, Laboratório de Nutrição Mineral de Plantas, Av. Fernando Correa da Costa, 2367, Bairro Boa Esperança, CEP 78060-900, Cuiabá (MT), Brasil. wlmperei@yahoo.com.br

3 Engenheira Florestal, Universidade Federal de Mato Grosso, Laboratório de Nutrição Mineral de Plantas, Av. Fernando Correa da Costa, 2367, Bairro Boa Esperança, CEP 78060-900, Cuiabá (MT), Brasil. isadora_pires_@hotmail.com / fernandafeboli@gmail.com 
of the plots with five, six and seven years old were, respectively, $0.54 ; 0.60$ and 0.58 . The average time of material renewal per plot, in years, was of 1.84 (671 days) for those with five, 1.67 (609 days) for those with six and 1.71 (624 days) for those with seven years old. The estimated time to decompose $50 \%$ of the litter material in the plots consisted in 1.28 years (467 days), 1.15 years (419 days) and 1.19 years (434 days) to the plots with five, six and seven years old, respectively. The estimated time to decompose $95 \%$ of the litter fall collected from plots with of five, six and seven years old consisted in 5.53 years (2018 days), 5.00 years (1825 days) and 5.14 years (1876 days), respectively.

Keywords: litter; Tectona grandis; decomposition rate.

\section{INTRODUÇÃO}

A produção de madeira em florestas plantadas sob regime sustentável, a industrialização e a comercialização de produtos de origem florestal constituem fontes produtivas geradoras de trabalho e riquezas. A teca, Tectona grandis Linn. F. é uma das espécies florestais mais plantadas em Mato Grosso e seu cultivo vem aumentando devido ao alto valor comercial da madeira. Os primeiros plantios de teca no Brasil tiveram início no final da década de 60, pela empresa Cáceres Florestal S.A., no município de Cáceres, em Mato Grosso. A região, além de possuir condições climáticas favoráveis, o solo de melhor fertilidade e os tratos silviculturais adequados e intensos contribuíram para a redução do ciclo de produção de 80 anos, na região de origem da teca, para 25 anos na região de Cáceres (TSUKAMOTO FILHO et al., 2003). Assim, o estado vem se destacando pela grande potencialidade para a implantação de plantios dessa espécie. Em um levantamento feito em Mato Grosso, Shimizu, Klein e Oliveira (2007) encontraram um total de 145.498 ha de plantios florestais em que 48.526 ha eram plantios de teca, seguidos pela seringueira com 44.896 ha e espécies do gênero Eucalyptus com 37.932 ha.

A serapilheira é um dos principais componentes do ecossistema florestal, sendo constituída por folhas, ramos, cascas, flores, frutos, sementes, raízes e resíduos animais que se depositam na superfície do solo, sendo as folhas consideradas o seu principal componente (GOLLEY et al., 1978; CARPANEZZI, 1980; DIAS; OLIVEIRA FILHO, 1997). É a principal via de transferência de nutrientes das plantas ao solo em ecossistemas florestais, além de permitir a existência de grande variedade de nicho para a fauna e microrganismos através do material orgânico depositado (CARPANEZZI, 1980; CUNHA et al., 1993). Sua decomposição libera ao solo elementos minerais que as plantas utilizam, sendo essencial na ciclagem de nutrientes.

Em estudo desenvolvido por Silva et al. (2009), em uma área de floresta de transição AmazôniaCerrado no norte de Mato Grosso, a produção de serapilheira apresentou variações sazonais com maior produção no período seco e predomínio da fração foliar em ambos os períodos. Almeida (2005), avaliando um povoamento de teca, observou variação na quantidade de serapilheira ao longo do ano. Essas variações estiveram entre 0 a 1,87 $\mathrm{Mg} \mathrm{ha}^{-1}$ para a teca com 0,5 ano e de 5,42 a 9,03 $\mathrm{Mg} \mathrm{ha}^{-1}$ para a teca com 5,5 anos, com média de $6,7 \mathrm{Mg}^{-1} \mathrm{ano}^{-1}$.

A produção de serapilheira é afetada por diversos fatores, tais como o tipo de vegetação, a latitude, a altitude, a precipitação, a temperatura, o relevo, a disponibilidade hídrica, a deciduidade, o estágio sucessional, as características do solo, entre outras, e, dependendo das características do ecossistema, um determinado fator pode prevalecer sobre os demais (FIGUEIREDO FILHO et al., 2003). A velocidade de sua decomposição também é significativamente influenciada pelo ambiente biótico e abiótico em que a decomposição ocorre. Essa complexa interação de fatores bióticos, como a decomposição, e de fatores abióticos, como o fluxo de energia pode, portanto, afetar a química do solo, a qualidade da serapilheira, a ciclagem de nutrientes e, por sua vez, na dinâmica das espécies florestais, no desenvolvimento e produtividade do ecossistema (SARIYILDIZ; ANDERSON; KUCUK, 2005).

O presente estudo teve como objetivos estimar a produção, a taxa de decomposição, o tempo médio de renovação e decomposição da serapilheira, em povoamentos da espécie Tectona grandis Linn. F. (Teca). 


\section{MATERIAL E MÉTODOS}

\section{Descrição da área experimental}

O presente estudo foi realizado em uma área pertencente à empresa Teca do Brasil Florestal Ltda., localizada no município de Nossa Senhora do Livramento - MT, coordenadas geográficas são $16^{\circ} 12^{\prime} 04^{\prime}$ de latitude S e $56^{\circ} 22$ 42" de longitude W. Segundo a classificação Köppen (1948), o clima é do tipo Aw, tropical, com estação seca de inverno. A precipitação média é de $1.300 \mathrm{~mm}^{2} \mathrm{no}^{-1}$, a temperatura média anual de $25^{\circ} \mathrm{C}$, com mínimas de $20^{\circ} \mathrm{C}$ e máximas de $32^{\circ} \mathrm{C}$ (CALDEIRA; OLIVEIRA, 2008). O solo predominante da área é classificado como Argissolo Vermelho-Amarelo-Distrófico (EMBRAPA, 2006). O estudo foi instalado em três talhões dos povoamentos de teca com idades de cinco, seis e sete anos, durante os meses de setembro de 2008 a agosto de 2009. Nestes talhões não foi realizada adubação pré ou pós-plantio e o preparo do solo foi feito com gradagem e terraceamento.

\section{Serapilheira depositada nos coletores e acumulada sobre o solo}

Em cada talhão das idades avaliadas utilizou-se uma área de um hectare $\left(10.000 \mathrm{~m}^{2}\right)$, na qual 20 coletores suspensos a $30 \mathrm{~cm}$ de altura do solo, com $0,64 \mathrm{~m}^{2}$ de área, foram dispostos aleatoriamente entre as linhas e fileiras de plantio para a estimativa da produção mensal de serapilheira de teca. Suas laterais foram feitas de madeira em formato quadrado e o centro com tela de nylon (sombrite $70 \%$ ) em formato côncavo para evitar perda de material e facilitar a drenagem.

Para a coleta da serapilheira acumulada sobre o solo, foram utilizados 20 quadrantes de madeira vazados, com $0,64 \mathrm{~m}^{2}$ de área, colocados próximos aos coletores suspensos, totalizando 40 coletores por hectare, em cada povoamento, sendo mantida uma distância da bordadura de $20 \mathrm{~m}$ para disposição dos coletores. A produção de serapilheira foi medida pelo material depositado nos coletores suspensos e a serapilheira acumulada sobre o solo pelo material acumulado nos moldes vazados.

A cada 30 dias, os conteúdos dos coletores suspensos e dos moldes vazados foram recolhidos e separados manualmente em três frações: folhas, ramos (menores que um centímetro de diâmetro) e miscelâneas (cascas, flores e frutos). Cada fração foi seca em estufa de circulação forçada de ar à temperatura de $70^{\circ} \mathrm{C}$, até peso constante, e posteriormente foram pesadas para a obtenção da massa seca.

\section{Estimativa da produção e da taxa de decomposição da serapilheira}

Com os valores obtidos de massa seca, estimou-se a produção por hectare da serapilheira depositada nos coletores e a acumulada sobre o solo. A taxa de decomposição foi estimada segundo o método proposto por Olson (1963), em que a taxa de decomposição (K) foi calculada utilizando os valores de produção anual de serapilheira $(\mathrm{L})$ e de seu acúmulo sobre o solo $\left(\mathrm{X}_{\mathrm{ss}}\right)$.

\section{Análise estatística dos dados}

Os resultados foram submetidos à análise de variância e, em caso de significância $(p<0,05)$, foi utilizado o teste Tukey 5\% para comparações das médias, pelo uso do aplicativo computacional SISVAR (FERREIRA, 2000). O coeficiente de correlação entre a produção de serapilheira e a precipitação pluviométrica foi estimado com base na equação do coeficiente de correlação linear de Pearson $(\mathrm{p}<0,05)$, por meio do software SPSS 16.0 for Windows.

\section{RESULTADOS E DISCUSSÃO}

\section{Produção de serapilheira}

Para os três talhões de teca estudados, as médias dos valores anuais de produção de serapilheira aumentaram de acordo com o tempo de implantação. O maior valor foi observado no talhão com idade de 
sete anos, que produziu 7.280,25 $\mathrm{kg} \mathrm{ha}^{-1}$, seguido pelos talhões com seis anos $\left(6.739,42 \mathrm{~kg} \mathrm{ha}^{-1}\right)$ e cinco anos $\left(6.419,61 \mathrm{~kg} \mathrm{ha}^{-1}\right)$, (Tabela 1).

TABELA 1: Produção média mensal de serapilheira nos talhões de teca estudados, no município de Nossa Senhora do Livramento - MT.

TABLE 1: Monthly average production of litter in studied teak stands in the city of Nossa Senhora do Livramento - MT state.

\begin{tabular}{|c|c|c|c|c|}
\hline \multirow{3}{*}{ Mês } & \multirow{3}{*}{ Fração } & \multicolumn{3}{|c|}{ Idade (anos) } \\
\hline & & 5 & 6 & 7 \\
\hline & & \multicolumn{3}{|c|}{$\mathrm{kg} \mathrm{ha}^{-1}$} \\
\hline \multirow{3}{*}{$\begin{array}{c}\text { Setembro } \\
2008\end{array}$} & Folhas & $1.338,02$ & $2.938,08$ & $2.757,57$ \\
\hline & Ramos & 14,87 & 24,87 & 29,85 \\
\hline & Miscelânea & 114,98 & 110,22 & 127,31 \\
\hline \multirow{3}{*}{$\begin{array}{c}\text { Outubro } \\
2008\end{array}$} & Folhas & 85,41 & 188,94 & 210,22 \\
\hline & Ramos & 18,13 & 9,79 & 11,53 \\
\hline & Miscelânea & 24,91 & 39,98 & 37,96 \\
\hline \multirow{3}{*}{$\begin{array}{c}\text { Novembro } \\
2008\end{array}$} & Folhas & 38,34 & 30,55 & 25,75 \\
\hline & Ramos & 17,63 & 12,27 & 40,30 \\
\hline & Miscelânea & 47,27 & 34,41 & 27,78 \\
\hline \multirow{3}{*}{$\begin{array}{c}\text { Dezembro } \\
2008\end{array}$} & Folhas & 177,63 & 50,94 & 46,40 \\
\hline & Ramos & 18,96 & 13,98 & 18,22 \\
\hline & Miscelânea & 45,50 & 15,44 & 23,87 \\
\hline \multirow{3}{*}{$\begin{array}{r}\text { Janeiro } \\
2009\end{array}$} & Folhas & 264,24 & 154,47 & 151,95 \\
\hline & Ramos & 19,54 & 18,96 & 22,27 \\
\hline & Miscelânea & 16,83 & 11,84 & 13,16 \\
\hline \multirow{3}{*}{$\begin{array}{c}\text { Fevereiro } \\
2009\end{array}$} & Folhas & 180,23 & 220,05 & 246,04 \\
\hline & Ramos & 23,27 & 23,70 & 20,38 \\
\hline & Miscelânea & 85,96 & 58,09 & 67,68 \\
\hline \multirow{3}{*}{$\begin{array}{r}\text { Março } \\
2009\end{array}$} & Folhas & 274,20 & 153,57 & 250,30 \\
\hline & Ramos & 99,09 & 23,89 & 35,63 \\
\hline & Miscelânea & 133,26 & 102,95 & 90,14 \\
\hline \multirow{3}{*}{$\begin{array}{c}\text { Abril } \\
2009\end{array}$} & Folhas & 170,11 & 173,07 & 328,95 \\
\hline & Ramos & 11,52 & 20,05 & 33,18 \\
\hline & Miscelânea & 71,34 & 72,95 & 66,23 \\
\hline \multirow{3}{*}{$\begin{array}{c}\text { Maio } \\
2009\end{array}$} & Folhas & 219,73 & 236,73 & 301,84 \\
\hline & Ramos & 23,31 & 6,75 & 9,88 \\
\hline & Miscelânea & 37,61 & 19,40 & 20,96 \\
\hline \multirow{3}{*}{$\begin{array}{r}\text { Junho } \\
2009\end{array}$} & Folhas & 384,83 & 314,73 & 433,74 \\
\hline & Ramos & 8,05 & 8,80 & 9,61 \\
\hline & Miscelânea & 29,14 & 19,43 & 14,33 \\
\hline \multirow{3}{*}{$\begin{array}{c}\text { Julho } \\
2009\end{array}$} & Folhas & 219,94 & 264,54 & 263,31 \\
\hline & Ramos & 4,28 & 5,50 & 6,54 \\
\hline & Miscelânea & 26,06 & 9,91 & 12,60 \\
\hline \multirow{3}{*}{$\begin{array}{r}\text { Agosto } \\
2009\end{array}$} & Folhas & $1.932,63$ & $1.184,46$ & $1.374,80$ \\
\hline & Ramos & 69,95 & 51,02 & 44,38 \\
\hline & Miscelânea & 172,84 & 115,09 & 105,59 \\
\hline Total & & $6.419,61$ & $6.739,42$ & $7.280,25$ \\
\hline C.V. $(\%)$ & & 66,75 & 59,77 & 50,92 \\
\hline
\end{tabular}

Em que: $\mathrm{CV} \%$ = Coeficiente de variação. 
Os valores encontrados neste trabalho foram maiores quando comparados aos encontrados por Corrêa (2005), de $1.070 \mathrm{~kg} \mathrm{ha}^{-1}$, que avaliou a ciclagem de nutrientes da teca com seis anos de idade em um sistema agroflorestal, porém, próximos aos encontrados por Almeida (2005), de $6.700 \mathrm{~kg} \mathrm{ha}^{-1}$ para um talhão de teca com cinco anos e cinco meses de idade. Diferenças na produção da serapilheira alteraram-se com a fase de desenvolvimento da planta e com a densidade do plantio (ALMEIDA, 2005). Em trabalho desenvolvido por Cunha (1997), em diferentes fases da sucessão secundária em uma floresta estacional decidual, no Rio Grande do Sul, a produção de serapilheira aumentou com o desenvolvimento da vegetação florestal, crescendo significativamente até ocorrer o fechamento do dossel.

Em estudo desenvolvido por Fernandes (2005), em um fragmento florestal localizado no município de Campo Verde - MT, foram quantificados valores de serapilheira de $9.038 \mathrm{~kg} \mathrm{ha}^{-1} \mathrm{em}$ uma área de floresta nativa e $6.363 \mathrm{~kg} \mathrm{ha}^{-1}$ para a capoeira. Kolm e Poggiani (2003), avaliando um povoamento de Eucalyptus grandis submetidos à prática de desbastes progressivos no município de Bofete - SP, encontraram 10.220 $\mathrm{kg} \mathrm{ha}^{-1}$ de valores da produção anual de serapilheira na testemunha (sem desbastes).

No período de 12 meses, o talhão de teca com cinco anos de idade apresentou a maior variação na produção de serapilheira, seguida do talhão com seis anos e de sete anos. Credita-se essa variação na produção da serapilheira durante o período do estudo aos fatores ambientais, fenológicos da planta, à prática silvicultural de desrama aplicada nos talhões e principalmente em função do estágio de desenvolvimento das plantas. Corrêa (2005), avaliando a ciclagem de nutrientes em um sistema agroflorestal em Rondônia, estimou, dentre as espécies avaliadas, a maior variação na produção de serapilheira da teca (CV 106,79\%).

Verifica-se na Figura 1 que as áreas com seis e sete anos apresentaram valores de produção próximos nos meses avaliados, demonstrando que os povoamentos, provavelmente, não atingiram a maturidade, pois foi observada crescente produção de serapilheira (Tabela 1).

Schumacher, Viera e Witschoreck (2008), estudando a serapilheira formada somente de acículas em um povoamento de Pinus taeda durante três anos (quinto ao sétimo ano de idade), constataram que a deposição de serapilheira aumentou com o passar do tempo devido ao progressivo desenvolvimento das plantas.

A maior produção de serapilheira ocorreu no final do período seco, nos meses de agosto e setembro (final do inverno e início da primavera), com menor deposição nos meses subsequentes, com o início da época chuvosa. Com a redução da precipitação, os povoamentos foram submetidos a estresse hídrico, e esse fator, relacionado com a fisiologia da espécie, contribuiu para a elevada produção de serapilheira nesse período. Segundo Silva et al. (2007), a maior deposição de serapilheira no período seco pode ser uma resposta da vegetação, que com a derrubada das folhas, reduziria a perda de água por transpiração.

Foi aplicada a correlação linear de Pearson entre os dados de precipitação e de produção mensal da serapilheira, obtendo-se uma correlação inversa e significativa $(r=-0,39)$, ou seja, 39\% na variação da produção de serapilheira foi explicada pela precipitação do período estudado. Silva et al. (2009), ao avaliar a dinâmica mensal da produção da serapilheira em uma floresta de transição Amazônia-Cerrado, localizada próximo ao município de Sinop-MT, obtiveram diferença significativa entre o período seco e chuvoso na produção de serapilheira.

Segundo Schumacher (1992), a quantidade de material orgânico depositado ao longo de um ano está relacionada principalmente às condições climáticas, sendo menor nas regiões frias e maior nas regiões equatoriais quentes e úmidas. A quantificação do folhedo depositado mensalmente deve ser analisada tendo em vista as variações das condições do ambiente, principalmente quanto à precipitação pluviométrica e temperatura (POGGIANI et al., 1987).

Ao avaliar a produção de serapilheira de um povoamento de taxi-branco (Sclerolobium paniculatum Vogel), com nove anos de idade, Mochiutti, Queiroz e Melém Junior (2006) observaram que a produção de serapilheira foi maior no período de menor precipitação (agosto a novembro), representando $74 \%$ de toda a serapilheira produzida durante o ano. A análise de correlação entre a deposição de serapilheira do taxibranco e as precipitações mensais, indicou que a redução da precipitação e a ocorrência de deficit hídrico estimularam as plantas a aumentar a queda de material senescente. A redução da área foliar funciona como um mecanismo de resistência ao déficit hídrico.

As folhas representaram $86 \%$ do total de serapilheira produzida, com produção anual de 17.586 


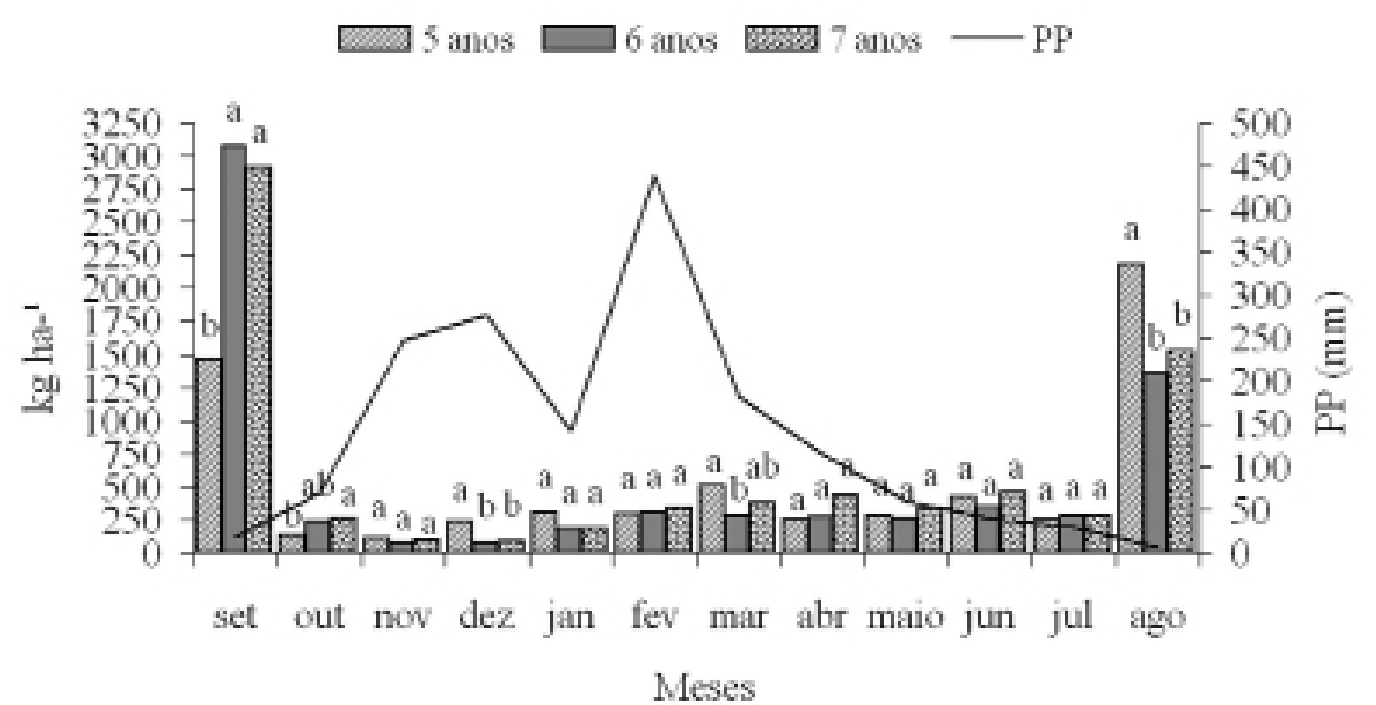

FIGURA 1: Produção média mensal de serapilheira de teca para os três talhões avaliados, e precipitação mensal durante o período de setembro de 2008 a agosto de 2009 na área de estudo, no município de Nossa Senhora do Livramento - MT. Médias seguidas por letras iguais nas colunas, dentro de cada mês, não diferem entre si pelo teste de Tukey a 5\%.

FIGURE 1: Monthly average of teak litter production for the evaluated three stands, and monthly precipitation from September 2008 to August 2009, in the city of Nossa Senhora do Livramento - MT. Means followed by the same letters in columns within each month, do not differ by Tukey test at $5 \%$.

$\mathrm{kg} \mathrm{ha}^{-1}$ e maior período de deposição nos meses mais secos, pelo fato da teca ser uma espécie caducifólia (Figura 2). Após esse período e com o início das chuvas, ocorreu uma deposição mínima desse material nos talhões.

Cunha e Costa (2000), analisando a dinâmica da serapilheira em um cambarazal, tipo de vegetação composta basicamente por indivíduos da espécie Vochysia divergens (cambará), no município de Nossa Senhora do Livramento - MT, verificaram que a média anual de serapilheira produzida foi de $174,4 \mathrm{~kg} \mathrm{ha}^{-1}$, com maiores valores de produção em maio e outro menos pronunciado em dezembro. No referido estudo, as folhas contribuíram decisivamente na produção anual da serapilheira do cambarazal, com $86 \%$ do total.

No estudo da deposição da serapilheira de duas espécies plantadas na Amazônia, Ceiba pentandra e de Virola surinamensis, entre 3,5 e 4,5 anos, a maior deposição de folhas para a primeira espécie ocorreu no período de junho até setembro, atingindo o máximo em julho. Para a segunda espécie, a maior deposição ocorreu durante os meses de agosto a outubro (NEVES; MARTINS; REISSMANN, 2001).

Os ramos da teca representaram $4 \%$ do total de serapilheira depositada, sendo que esse pequeno valor é atribuído, em parte, por se ter avaliado apenas os ramos menores que um centímetro de diâmetro. Atribuiu-se a maior deposição de ramos no mês de março à alta precipitação ocorrida no mês anterior.

No mês de janeiro, a produção total de serapilheira no talhão de cinco anos aumentou devido à prática da desrama neste talhão. No talhão com seis e sete anos, a desrama foi realizada no mês subsequente, razão pela qual o material produzido aumentou, indicando que essa prática silvicultural interferiu na dinâmica natural de deposição de material vegetal.

A fração miscelânea representou $10 \%$ do total de serapilheira, sendo que a menor deposição desse material ocorreu no período inicial de floração da teca, meses de dezembro e janeiro, com aumento da quantidade nos meses subsequentes devido à formação dos seus frutos (drupas). Segundo Tewari (1992), os frutos da teca amadurecem de novembro a janeiro e caem de fevereiro a abril. 


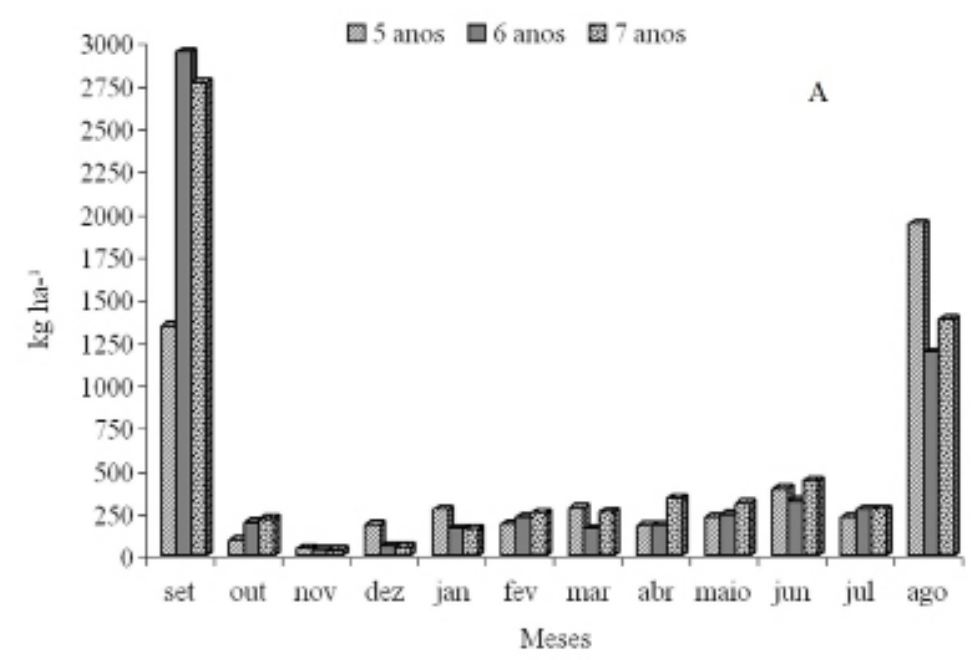

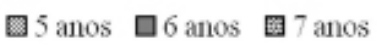
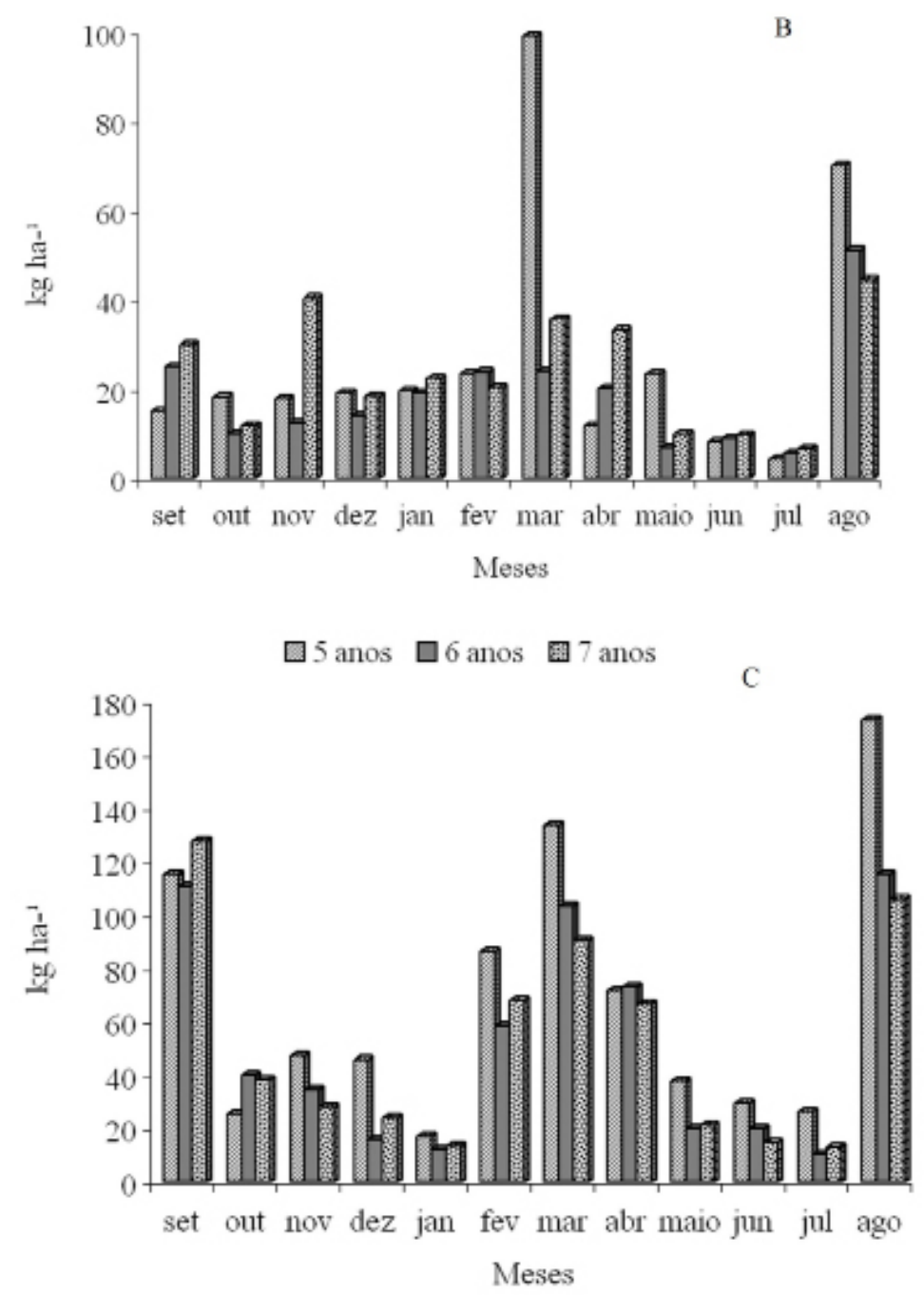

FIGURA 2: Valores médios mensais de produção de folhas (A), ramos (B) e miscelâneas (C) da serapilheira de teca, em talhões no município de Nossa Senhora do Livramento - MT.

FIGURE 2: Monthly average values of leaf production (A), branches (B) and miscellaneous (C) from teak leaf litter, in stands in the city of Nossa Senhora do Livramento - MT state. 
Segundo Kato (1995), em plantios de Bertholletia excelsa H. B. K. (castanheira-do-Brasil) com dez anos de idade implantadas em linhas de enriquecimento na floresta primária e em plantios com dez e cinco anos implantados sobre pastagens degradadas, no município de Itacoatiara - AM, a maior produção de serapilheira ocorreu durante a estação seca do ano, em setembro, com produção anual de $7.040 \mathrm{~kg} \mathrm{ha}^{-1}$, de $1.280 \mathrm{~kg} \mathrm{ha}^{-1}$ e de $670 \mathrm{~kg} \mathrm{ha}^{-1}$, respectivamente.

\section{Taxa de decomposição da serapilheira}

As constantes de decomposição da serapilheira $(\mathrm{K})$ nos talhões com cinco, seis e sete anos de idade foram, respectivamente, de 0,54;0,60 e 0,58 (Tabela 2). Para Olson (1963), são consideradas em estado de equilíbrio dinâmico as florestas tropicais cujos valores de $\mathrm{K}$ se situam entre 1,0 e 4,0. Os valores de $\mathrm{K}$ encontrados neste estudo foram menores que os estabelecidos por esse autor, indicando que a teca apresenta uma lenta taxa de decomposição.

Os valores obtidos foram maiores que os encontrados por Corrêa (2005), de 0,15 em plantas de teca com seis anos e de 0,31 para a espécie Schizolobium amazonicum (bandarra), também com seis anos de idade, dentre outras espécies componentes de um sistema agroflorestal, em Rondônia - RO. De acordo com o mesmo autor, o menor valor de $\mathrm{K}$ obtido para teca foi devido à baixa taxa de decomposição do material produzido pela espécie. Esse autor sugere ainda que essas variações nos valores da constante $\mathrm{K}$ sejam decorrentes das espécies, da produção e qualidade da serapilheira, das condições climáticas e da composição da microbiota e da mesofauna.

A lenta taxa de decomposição do material produzido pela teca é devida, em parte, às características fenológicas da espécie, sendo que as folhas chamam a atenção pelo tamanho, que podem alcançar de 40 a $80 \mathrm{~cm}$ de comprimento, formando uma manta sobre o solo, especialmente nos meses mais secos do ano, expressando as reações orgânicas diante do estímulo das variações do ambiente.

Segundo Schindler e Gessner (2009), as taxas de decomposição são em grande parte controladas pelo teor de lignina da serapilheira. Pimenta et al. (2011) relacionaram a menor decomposição no reflorestamento à maior luminosidade e à menor umidade relativa, devido à maior abertura do dossel.

Kolm e Poggiani (2003), ao estimar a taxa de decomposição da serapilheira em plantações de Eucalyptus grandis com 20 anos, em diferentes intensidades de desbaste, com $0 \%, 67 \%$ e $83 \%$, encontraram respectivamente $0,56,0,81$ e 0,70 para os valores da constante de decomposição (K). Em trabalho realizado por Zaia e Gama-Rodrigues (2004), no qual avaliaram plantios de Eucalyptus grandis, Eucalyptus camaldulensis e Eucalyptus pellita na idade de seis anos, localizados no município de Campos dos Goytacazes - RJ, observaram que o Eucalyptus grandis teve o maior coeficiente de decomposição $(\mathrm{K}=1,00)$ do que o Eucalyptus camaldulensis $(\mathrm{K}=0,59)$ e Eucalyptus pellita $(\mathrm{K}=0,51)$. Os autores atribuíram o menor acúmulo de serapilheira do Eucalyptus grandis à sua alta qualidade orgânica (por exemplo, menores teores de lignina).

Delitti (1984), abordando alguns aspectos da ciclagem de minerais na mata ciliar, no campo cerrado e a floresta de Pinus elliottii Engelm. var. elliottii, localizado em Mogi-Guacu - SP, observou que a constante de decomposição foi maior na mata ciliar $(K=0,49)$ do que nos demais ecossistemas (cerrado, $K=0,27$; pinhal, $\mathrm{K}=0,25)$.

TABELA 2: Taxas de decomposição (K), tempo médio de renovação da serapilheira $(1 / \mathrm{K})$ e tempos necessários para a decomposição de $50 \%$ (t 0,5$)$ e $95 \%$ (t 0,05$)$ da serapilheira de teca.

TABLE 2: Decomposition rates $(\mathrm{k})$, average time of the litter renewal $(1 / \mathrm{k})$ and required time for teak litter decomposition of 50\% (t 0.5$)$ and $95 \%(\mathrm{t} 0.05)$.

\begin{tabular}{ccccc}
\hline IDADE & $\mathrm{K}$ & $1 / \mathrm{K}$ & $\mathrm{t} 0,5$ & $\mathrm{t} 0,05$ \\
\hline & & $\ldots \ldots \ldots \ldots \ldots \ldots \ldots \ldots \ldots \ldots \ldots \ldots \ldots \ldots \ldots \ldots \ldots \ldots \ldots \ldots \ldots \ldots \ldots \ldots \ldots \ldots \ldots \ldots \ldots \ldots \ldots \ldots \ldots \ldots \ldots \ldots$ & \\
\hline 5 ANOS & 0,54 & 1,84 & 1,28 & 5,53 \\
6 ANOS & 0,60 & 1,67 & 1,15 & 5,00 \\
7 ANOS & 0,58 & 1,71 & 1,19 & 5,14 \\
\hline
\end{tabular}


O tempo médio de renovação da serapilheira nos talhões com cinco, seis e sete anos foi de 1,84 anos (671 dias); de 1,67 anos (609 dias) e de 1,71 anos (624 dias), respectivamente.

Para a decomposição de 50\% da serapilheira o tempo médio estimado foi de 1,28 anos (467 dias); de 1,15 anos (419 dias) e de 1,19 anos (434 dias) para as árvores com cinco, seis e sete anos, respectivamente. Para o desaparecimento de $95 \%$ da serapilheira foi de 5,53 anos (2.018 dias); de 5,00 anos (1.825 dias) e de 5,14 anos (1.876 dias) para a mesma sequência de idades.

Fernandes (2005) estimou o tempo necessário para a decomposição de 50\% e 95\% da serapilheira na florestal nativa em 1,31 e 5,67 anos, respectivamente, e 0,94 e 4,10 anos na capoeira. O tempo médio de renovação da serapilheira em plantações de Eucalyptus grandis com 20 anos, sem desbaste, foi de 1,77 anos e os tempos médios necessários para a decomposição de 50\% e 95\% da serapilheira foi 1,24 e 5,36 anos (KOLM; POGGIANI, 2003).

\section{CONCLUSÕES}

A produção de serapilheira aumentou com a idade do povoamento. A taxa de decomposição da serapilheira dos talhões com cinco anos foi de 0,54; com seis anos, de 0,60 e com sete anos, de 0,58. O menor tempo médio de renovação e o menor tempo necessário para a decomposição de $50 \%$ e $95 \%$ da serapilheira foi observado no talhão com seis anos.

\section{REFERÊNCIAS}

ALMEIDA, E. M. Determinação do estoque de carbono em Teca (Tectona grandis L.F.) em diferentes idades. 2005. 71 f. Dissertação (Mestrado em Agricultura Tropical) - Universidade Federal de Mato Grosso, Cuiabá, 2005.

CALDEIRA, S. F.; OLIVEIRA, D. L. C. Desbaste seletivo em povoamentos de Tectona grandis com diferentes idades. Acta Amazônica, Manaus, v. 38, n. 2, p. 223-228, 2008.

CARPANEZZI, A. P. Deposição de material orgânico e nutrientes em uma floresta natural e em uma plantação de eucaliptos no interior do Estado de São Paulo. 1980. 107 f. Dissertação (Mestrado em Engenharia Florestal) - Escola Superior de Agricultura "Luiz de Queiroz", Universidade de São Paulo, Piracicaba, 1980.

CORRÊA, F. L. O. Ciclagem de nutrientes em sistema agroflorestal com espécies frutíferas e florestais em Rondônia, Brasil. 2005. 110 f. Tese (Doutorado em Agronomia) - Universidade Federal de Lavras, Lavras, 2005.

CUNHA, C. N.; COSTA, C. P. Dinâmica de serapilheira em Vochysia divergens (Pohl) no cambarazal da Fazenda Retiro Novo, Pantanal de Poconé, MT. In: SIMPÓSIO SOBRE RECURSOS NATURAIS E SÓCIO-ECONÔMICOS DO PANTANAL. OS DESAFIOS DO NOVO MILÊNIO, 3., 2000, Corumbá. Anais... Disponível em: <http://www.cpap.embrapa.br/agencia/.../NUNESDACUNHA-026.pdf>. Acesso em: 01 nov. 2010.

CUNHA, G. C. et al. Dinâmica nutricional em Floresta Estacional Decidual com ênfase aos minerais provenientes da deposição da serapilheira. Ciência Florestal, Santa Maria, v. 3, n. 1, p. 35-64, dez. 1993.

CUNHA, G. C. Aspectos da ciclagem de nutrientes em diferentes fases sucessionais de uma Floresta Estacional do Rio Grande do Sul. 1997. 86 f. Dissertação (Mestrado em Ciências Florestais) - Escola Superior de Agricultura "Luiz de Queiroz", Universidade de São Paulo, Piracicaba, 1997.

DELITTI, W. B. C. Aspectos comparativos da ciclagem de nutrientes minerais na mata ciliar, no campo cerrado e na floresta implantada de Pinus elliottii var. elliottii. 1984. 248 f. Tese (Doutorado em Ecologia Vegetal) - Instituto de Botânica, Universidade de São Paulo, São Paulo, 1984.

DIAS, H. C. T.; OLIVEIRA FILHO, A. T. Variação temporal e espacial da produção de serapilheira em uma área de Floresta Estacional Semidecídua Montana em Lavras-MG. Revista Árvore, Viçosa, MG, v. 21, n. 1, p. 11-26, 1997.

EMBRAPA. Centro Nacional de Pesquisa de Solos. Sistema brasileiro de classificação de solos. 2. ed. Rio 
de Janeiro: EMBRAPA, 2006. 306 p.

FERNANDES, F. C. S. Produção de liteira, concentração e estoque de nutrientes em Floresta Nativa e Capoeira. 2005. 83 f. Dissertação (Mestrado em Agricultura Tropical) - Universidade Federal de Mato Grosso, Cuiabá, 2005.

FERREIRA, D. F. Sistema para análise de variância para dados balanceados: SISVAR. Lavras: UFLA, 2000 .

FIGUEIREDO FILHO, A. et al. Avaliação estacional da deposição de serapilheira em uma Floresta Ombrófila Mista localizada no sul do Estado do Paraná. Ciência Florestal, Santa Maria, v. 13, n. 1, p. 11-18, 2003.

GOLLEY, F. B. et al. Ciclagem de minerais em um ecossistema de floresta tropical úmida. São Paulo: EPU; EDUSP, 1978. 256 p.

KATO, A. K. Dinâmica da entrada de nutrientes via liteira em plantios de Castanheira-do-Brasil (Bertholletia excelsa H. B. K.) em ecossistemas de pastagens degradadas e de floresta primária. 1995. 180 f. Tese (Doutorado em Ciências Biológicas) - Instituto Nacional de Pesquisas da Amazônia; Universidade Federal do Amazonas, Manaus, 1995.

KOLM, L.; POGGIANI, F. Ciclagem de nutrientes em povoamentos de Eucalyptus grandis submetidos à prática de desbastes progressivos. Scientia Forestalis. Piracicaba, n. 63, p. 79-93, jun. 2003.

KÖPPEN, W. Climatologia: con un estudio de los climas de la tierra. México: [s. n.], 1948. 479 p.

MOCHIUTTI, S.; QUEIROZ, J. A. L.; MELÉM JUNIOR, N. J. Produção de serapilheira e retorno de nutrientes de um povoamento de Taxi-branco e de uma Floresta Secundária no Amapá. Boletim de Pesquisa Florestal, Colombo, n. 52, p. 3-20, jan./jun. 2006.

NEVES, E. J. M.; MARTINS, E. G.; REISSMANN, C. B. Deposição de serapilheira e de nutrientes de duas espécies da Amazônia. Boletim de Pesquisa Florestal, Colombo, n. 43, p. 47-60, jul./dez. 2001.

OLSON, J. S. Energy storage and the balance of producers and decomposers in ecological systems. Ecology, Brooklyn, v. 44, n. 2, p. 322-331, 1963.

PIMENTA, J. A. et al. Produção de serapilheira e ciclagem de nutrientes de um reflorestamento e de uma floresta estacional semidecidual no sul do Brasil. Acta Botanica Brasílica, Feira de Santana, v. 25, n. 1, p. 53-57, 2011.

POGGIANI, F. et al. Quantificação da deposição de folhedo em talhões experimentais de Pinus taeda, Eucalyptus viminalis e Mimosa scabrella plantados em uma área degradada pela mineração do Xisto Betuminoso. IPEF, Piracicaba, n. 37, p. 21-29, dez. 1987.

SARIYILDIZ, T.; ANDERSON, J. M.; KUCUK, M. Effects of tree species and topography on soil chemistry, litter quality, and decomposition in Northeast Turkey. Soil Biology \& Biochemistry, v. 37, n. 9, p. 1695-1706, 2005.

SCHINDLER, M. H.; GESSNER, M. O. Functional leaf traits and biodiversity effects on litter decomposition in a stream. Ecology, Brooklyn, v. 90, n. 6, p. 1641-1649, jun. 2009.

SCHUMACHER, M. V. Aspectos da ciclagem de nutrientes e do microclima em talhões de Eucalyptus camaldulensis Dehnh., Eucalyptus grandis Hill ex Maiden e Eucalyptus torelliana F. Muell. 1992. 87 f. Dissertação (Mestrado em Ciências Florestais) - Escola Superior de Agricultura "Luiz de Queiroz", Universidade de São Paulo, Piracicaba, 1992.

SCHUMACHER, M. V.; VIERA, M.; WITSCHORECK, R. Produção de serapilheira e transferência de nutrientes em área de segunda rotação com floresta de Pinus taeda L. no município de Cambará do Sul, RS.

Ciência Florestal, Santa Maria, v. 18, n. 4, p. 471-480, out./dez. 2008.

SHIMIZU, J. Y.; KLEIN, H.; OLIVEIRA, J. R. V. Diagnóstico das plantações florestais em Mato Grosso 2007. Cuiabá: Central de Texto, 2007.

SILVA, C. J. et al. Produção de serapilheira no Cerrado e Floresta de Transição Amazônia-Cerrado do Centro-Oeste brasileiro. Acta Amazônica, Manaus, v. 37, n. 4, p. 543-548, 2007.

SILVA, C. J. et al. Contribuição de folhas na formação da serapilheira e no retorno de nutrientes em floresta de transição no norte de Mato Grosso. Acta Amazônica, Manaus, v. 39, n. 3, p. 591-600, set. 2009.

TEWARI, D. N. A monograph on Teak (Tectona gandis Linn.f.). Dehra Dun: International Book Distributors, 1992.

TSUKAMOTO FILHO. A. A. et al. Análise econômica de um plantio de Teca submetido a desbastes. 
Revista Árvore, Viçosa, MG, v. 27, n. 4, p. 487-494, 2003.

ZAIA, F. C.; GAMA-RODRIGUES, A. C. Ciclagem e balanço de nutrientes em povoamentos de eucalipto na região Norte Fluminense. Revista Brasileira de Ciências do Solo, Viçosa, MG, v. 28, n. 5, p. 843-852, set./out. 2004. 